\title{
A Test Chamber Investigation of the Effect of Charging on Aerosol Deposition on Indoor Surfaces
}

\author{
Tashfeen Muhammad Hammad Ud Din*, James A. McGrath, Miriam A. Byrne \\ School of Physics, Ryan Institute's Centre for Climate \& Air Pollution Studies, National University of Ireland Galway, \\ University Road, Galway, H91 CF50, Ireland
}

\begin{abstract}
The deposition of radioactive aerosols, which are potentially harmful to human health, is influenced by their ability to self-charge via ionization. This relationship which has rarely been studied was investigated by corona-charging particles in three sizes $(0.5 \mu \mathrm{m}, 1.0 \mu \mathrm{m}$ and $2.0 \mu \mathrm{m})$ in a test chamber to levels representative of radioactive aerosols. The aerosol deposition velocities were calculated for each size fraction under a variety of conditions, which consisted of using two chamber airflow rates, three charging regimes (producing a strong positive charge, a strong negative charge, and no corona charge), and three interior wall surfaces (aluminum, wallpaper, and polyethylene). No significant difference in deposition velocity was detected between the charged aerosols, regardless of their polarity, but the deposition velocity of the charged aerosols exceeded that of the uncharged aerosols by as much as $72 \%$. All of the size fractions, irrespective of the charging regime, exhibited the highest deposition rates when the chamber walls were lined with polyethylene, with values that were 4-8 times higher than those calculated for aluminum lining.
\end{abstract}

Keywords: Aerosol charge; Radioactive aerosols; Fine aerosols; Surface charge; Enhanced deposition.

\section{INTRODUCTION}

Electrically charged aerosols arise in the environment from a number of sources, one of which is nuclear accidents. Nuclear accidents can pose a large-scale risk to human health due to long-range transport of radioactive aerosols. Radionuclides originating from the Fukushima nuclear accident, which occurred in Japan in 2011, were found in food and water samples in Europe and also in the Pacific region (Lujaniene et al., 2011; Homoki et al., 2013; Kameník et al., 2013; Potiriadis et al., 2013; McKenzie and Dulai, 2017).

Human exposure to radioactive aerosols occurs via inhalation, ingestion, and dermal contact (Kannan et al., 2001; Andersson et al., 2006; Homoki et al., 2013; Potiriadis et al., 2013). Beta-emitting particles deposited on skin can cause burns and skin cancer because of their ionization energy (Fogh and Andersson, 2000). The exposure to radiation through inhalation and ingestion of radionuclides from the Chernobyl accident resulted in an increased number of thyroid cancer cases (Acar et al., 2011; Thomas et al., 2011). It is the process of aerosol deposition that alters the route of exposure, and

\footnotetext{
* Corresponding author.

Tel.: 1+35391495289

E-mail address: t.hammaduddin1@ @uigalway.ie
}

in the case of radioactive aerosols, the deposition mechanism is influenced by the fact that aerosols are electrically charged.

The self-charging property of radioactive aerosols distinguishes it from other aerosol types. Radioactive species impart a surface charge on the aerosols, which can be negative or positive, depending on whether the charging mechanism is electron emission or ion diffusion (Kweon et al., 2013; Kim et al., 2014). Aerosols acquire charge due to both beta decay and alpha decay, and it is not only the aerosols but also the surrounding air that becomes ionized (Gensdarmes et al., 2001). Radioactive aerosols may contain a mixture of radionuclides (Cuddihy et al., 1989; Querfeld et al., 2019), and this will influence the charge; many other factors also contribute, including the specific radionuclide activity, the aerosol concentration and particle size, and the asymmetry parameter of the ion flux. A radioactive aerosol can be partially neutralized by ion pairs produced in the surrounding region from the decay of other radioactive aerosols in its vicinity, but this may change when there is dilution with air that is less heavily ionized; in this case, the radioactive aerosol concentration will decrease, and the ability of radioactive decay-generated ion pairs to interact with neighboring aerosols will decrease. Ion pair interaction may also be affected when particles are in a confined geometry or if an electric field is introduced (Clement and Harrison, 2000; Gensdarmes et al., 2001).

There are typically $10^{3}$ ions $\mathrm{cm}^{-3}$ in indoor air and these ions interact with aerosols, altering their charge status. In 
theory, an aerosol can carry zero charge, but this rarely happens as particles are in constant interaction with ions present in the air. In Boltzmann equilibrium there is a statistical probability that some particles might have no charge while others will have equal concentrations of positive and negative charges, but the overall aerosol charge distribution is symmetrically about zero (Hinds, 1999). The magnitude of charge typically found on radioactive aerosols ranges from fewer than 10 negative elementary charges to more than 100 positive charges (Gensdarmes et al., 2001; Kim et al., 2015). The amount of charge an aerosol can have depends on its particle size and surface area, with larger particles, having larger surface area, holding more charge than smaller particles $(\mathrm{Wu}$ et al., 2005).

Aerosol charge affects their distance travelled, and particle interaction with surfaces and with other particles (Mayya et al., 2002). Charged aerosols move due to the Coulomb force, which can be both attractive and repulsive, and the attractive image force, a polarization phenomenon occurring when charged particles move towards a conducting surface, and frequently neglected due to its range (Lai, 2006). The electrical mobility of an aerosol is the ratio of its terminal velocity in an electric field to the strength of the electric field. The electric mobility of an aerosol depends on the aerosol size and its electrical charge. Smaller particles or particles with higher charges thus show higher mobility in the presence of an electric field (Lee and Rasaiah, 1994; Schery, 2001).

Indoor exposure to radioactive aerosols, following an accident, is an important consideration, as it is well known that populations of developed countries spend up to 85-90\% of their time indoors (Chen and Zhao, 2011), and may be subject to exposure from indoor-penetrating radionuclides. Yoshida-Ohuchi et al. (2016) investigated the presence of radionuclides in ninety-five houses and found that ${ }^{134} \mathrm{Cs}$ and ${ }^{137} \mathrm{Cs}$ presence was dominant and that the relative amount was proportional to the distance from the Fukushima nuclear accident site. However, the benefits of sheltering, following an accident, are long recognized (Leung, 1992); following the Fukushima accident, the concentration of radionuclides indoor and outdoor were measured simultaneously and air decontamination factors of 0.64 for ${ }^{131} \mathrm{I}$ and 0.58 for ${ }^{137} \mathrm{Cs}$ were calculated (Ishikawa et al., 2014).

Kulmala et al. (1999) developed a computational model which predicted indoor aerosol concentrations, surface accumulation, and an indoor/outdoor ratio for radioactive aerosols. Tan et al. (2015) derived an airborne sheltering factor (ASF) for Fukushima-originating aerosols using indoor/outdoor radionuclide concentration data gathered from houses after the accident, together with values of air exchange rate, and indoor surface area and volume. The deposition velocity values used in the model for ${ }^{131} \mathrm{I}$ and ${ }^{137} \mathrm{Cs}$ were $2.50 \times 10^{-5} \mathrm{~m} \mathrm{~s}^{-1}$ and $1.94 \times 10^{-5} \mathrm{~m} \mathrm{~s}^{-1}$ but the charge on the aerosols was not measured. Aerosol deposition studies are reviewed below, with a view to assessing whether sufficient data exist on charged aerosol deposition.

Hussein et al. (2009b) studied, both experimentally and with a model, the deposition rate of aerosols on surfaces with different roughness in a test chamber and observed an increase in deposition rate depending upon the roughness, mixing intensity, and aerosol size. Additionally, Hussein et al. (2009a) investigated the effect of turbulent intensity from ventilation on aerosol deposition rate on surfaces with different roughness in a test chamber using a semi-empirical model and it was observed that with increased roughness and air mixing intensity the deposition rate was 10 times higher. Byrne et al. (1995) conducted test chamber experiments using monodisperse tracer aerosols under turbulent conditions, to measure aerosol deposition rates. Thatcher et al. (2002) studied the effect of furnishings and air speeds on the exposure and deposition of aerosols indoors using a room with different furnishing and air speed levels. In a furnished room compared to a bare room, an increase in deposition loss rate by a factor of 2.6 was observed and additionally, by increasing the airspeed from $<5 \mathrm{~cm} \mathrm{~s}^{-1}$ to $19 \mathrm{~cm} \mathrm{~s}^{-1}$ there was an increase in deposition rate by factors in the range of 1.3-2.4. Kim et al. (2019) investigated the effect of humidity and airflow rate, and flow direction on the deposition of aerosols in a chamber; the highest deposition was observed under humid conditions with an upward airflow direction. However, none of these studies considered the possibility of the aerosols carrying any charge, and what effect this would have on measured deposition rates. This was also the case in a number of other aerosol deposition studies (Abadie et al., 2001; El Hamdani et al., 2008; Liu et al., 2018; Wang et al., 2019).

There are a small number of studies where aerosol deposition enhancement due to electrostatic effects has been demonstrated. Stein et al. (1973) investigated the decay of aerosols in plastic chamber where charged aerosols have shown a higher decay rate as compare to uncharged aerosols, and a similar observation was made in a later study by McMurry and Rader (1985). Again, the aerosol charge status was not explicitly described in these studies.

Turner et al. (1989) presented a theoretical model to investigate the deposition of aerosols for clean-room workbench conditions and suggested that electrostatics had a significant impact. Cooper et al. (1989) also investigated the effect of electrostatics on flat surfaces and observed 180fold increase in deposition velocity of $0.1 \mu \mathrm{m}$ aerosols under high electric potential $(2000 \mathrm{~V})$. Lee and Yook (2014) examined aerosol deposition velocity under the influence of electrophoresis and thermophoresis under a $0 \mathrm{~V} \mathrm{~cm}^{-1}$ electric field. It was observed that thermophoresis influenced aerosol deposition on semiconductor wafers but deposition under a high electric field reduced the effects of thermophoresis. As before, these studies do not describe in detail the charge characteristics of the aerosols that are under investigation.

Building envelope shielding and indoor aerosol deposition can provide some degree of protection from radioactive aerosol exposure, but this is a poorly understood topic, as aerosol deposition measurements to date have focused on particles which, unlike radioactive aerosols, do not carry appreciable electrical charge. To fill this knowledge gap, and to contribute generally to a better understanding of charged aerosol deposition, the objective of the current work is to carry out test chamber measurements of aerosol deposition velocities using particles that carry an electrical charge that is representative of radioactive aerosols. To select representative aerosol size ranges for investigation, reference was made to 
values reported in literature. Dorrian (1997) reviewed the studies that followed the Chernobyl accident and found that the particles were in the range of $0.3-18 \mu \mathrm{m}$. After the Fukushima nuclear accident, radioactive aerosols ${ }^{131} \mathrm{I},{ }^{137} \mathrm{Cs}$, and ${ }^{134} \mathrm{Cs}$ found in France, Germany, Greece, Poland, and the Czech Republic were in the size range of $0.17-0.71 \mu \mathrm{m}$ (Masson et al., 2013).

Enhanced understanding of radioactive aerosols is not the only application of this study; there are other areas where it could be applied such as in the design of indoor air ionizers. The operating principle of air ionizers is corona discharge where emitted ions attract to particulate matter indoors, thereby enhancing deposition on indoor surfaces such as walls (Berry et al., 2007). Previous studies have investigated the aerosol deposition enhancement potential of ionizers when challenged with selected particle size regimes (Grabarczyk, 2001) and indoor aerosol types (Waring and Siegel, 2011), but further investigation is merited.

\section{METHODS}

Fig. 1 shows the overall experimental setup used in this study. Aerosol decay rate measurements were made in an aluminum chamber with an air exchange rate of $0.99 \mathrm{~h}^{-1}$. The air exchange rate was measured by injecting $\mathrm{CO}_{2}$ into the chamber and measuring its decay over time using a probe (GrayWolf Sensing Solutions; Shelton, CT, USA) (Persily, 2016). The dimensions of the chamber were $1.4 \mathrm{~m} \times 1.4 \mathrm{~m}$ $\times 1.0 \mathrm{~m}$. Homogeneous mixing of air inside the chamber was achieved using a downwards-facing $20 \mathrm{~W}$ fan on the ceiling in the center of the chamber. Using the fan, two different air velocities were generated in the chamber, and the air velocities were measured using a hot-wire anemometer probe (Testo 405i; Testo, West Chester, PA, USA); the lower average air velocity was $0.275 \pm 0.075 \mathrm{~m} \mathrm{~s}^{-1}$ in the center of the chamber $\left(0.023 \pm 0.013 \mathrm{~m} \mathrm{~s}^{-1}\right.$ at the chamber walls $)$ and the higher average air velocity was $0.90 \pm 0.10 \mathrm{~m} \mathrm{~s}^{-1}$ in the center of the chamber $\left(0.085 \pm 0.035 \mathrm{~m} \mathrm{~s}^{-1}\right.$ at the chamber walls). To put these values in context, it can be noted that air velocities between $0.1-0.9 \mathrm{~m} \mathrm{~s}^{-1}$ were observed in thermal comfort studies in offices (Gong et al., 2006). Based on the flow characteristics and the chamber dimensions in the present study, a Reynolds number was estimated which exceeds the acceptable threshold flow independence when comparability of the current work to real indoor environments is considered (Bauman et al., 1991).

Based on the size and charge ranges of radioactive aerosols measured in studies that are cited in the literature review section of this paper, three particle fractions with mean aerodynamic diameters of $0.5 \mu \mathrm{m}, 1.0 \mu \mathrm{m}$, and $2.0 \mu \mathrm{m}$ were chosen for this study.

\section{Instruments, Materials, and Experimental Setup}

Prior to the experiment, the chamber and its interior surfaces were cleaned, and a period of 15 minutes was allowed to establish an ambient aerosol concentration. The three separate monodisperse polystyrene latex particle (Polybead Carboxylate; Polysciences, Inc., Warrington, PA, USA) distributions were separately injected into the chamber (via an entry port on the left wall, $0.11 \mathrm{~m}$ from the ceiling) in individual runs, using a nebulizer (Respironics SideStream Disposable Nebuliser 4445A; Philips N.V., Chichester, UK). The delivery air was from a compressed air source, at a flow rate in the range of 6-8 $\mathrm{L} \mathrm{min}^{-1}$; appropriate flow rate values were chosen to match the working limits of a corona charger, which the aerosols passed through before entering the test chamber. A first-generation Unipolar Diffusion Aerosol Charger (UDAC; Cambustion Ltd, Cambridge, UK) was used with its outlet connected directly to the chamber; the corona unit could deposit charges of a single polarity in separate experimental runs. This was possible because the UDAC was modified to operate as a bipolar corona charger and hence could be used in both positive and negative unipolar modes. The nebulized aerosols passed through a drying tube before entering the corona charger. The aerosol charger could produce free ions but because of the large aerosol concentration passing through the charger it was considered that this concentration was low and would, in any case, be diluted by the chamber air, thus minimizing its impact on measured current.

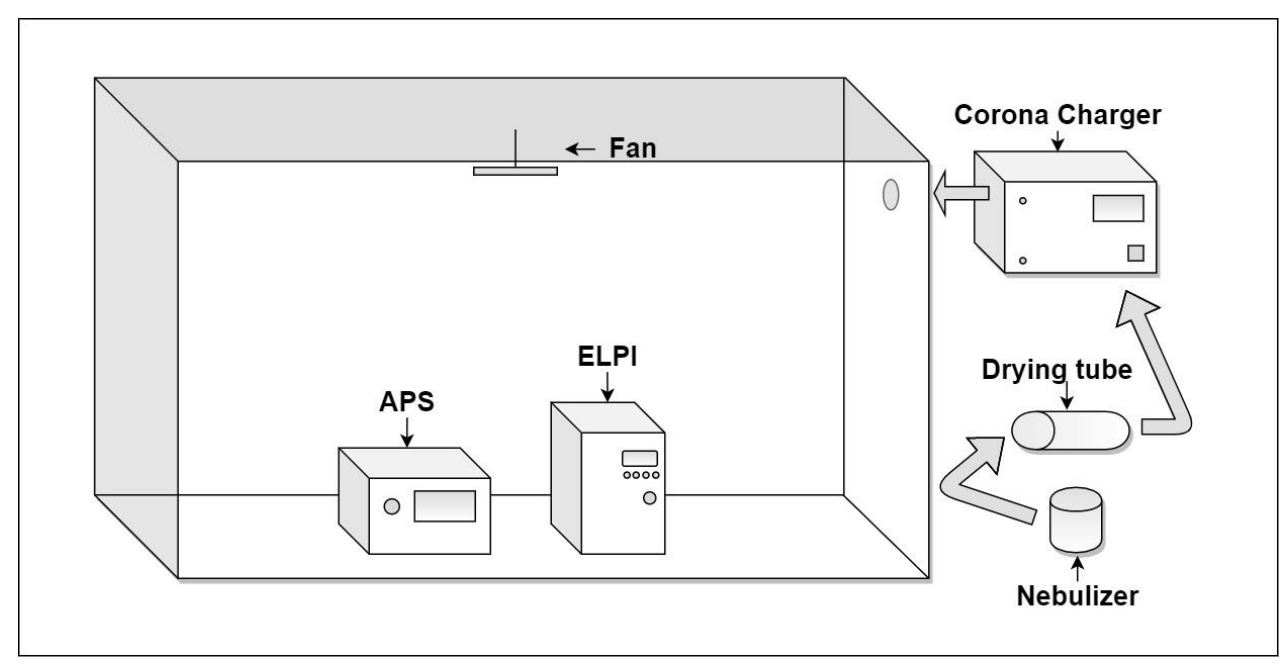

Fig. 1. Experimental setup. 
An Aerodynamic Particle Sizer (APS; Model 3321; TSI Inc., St. Paul, MN, USA) and Classic Electrical LowPressure Impactor (ELPI; Dekati Ltd., Tampere, Finland) were both placed in the center of the chamber. The APS monitored aerosol concentration for 30 minutes while the ELPI simultaneously monitored charge. These data were used to measure deposition velocity using Eqs. (1)-(3):

$$
\begin{aligned}
& C_{t}=C_{0} e^{-\lambda t} \\
& \lambda=\lambda_{d}+\lambda_{a} \\
& v_{d}=\lambda_{d} /\left(\frac{A}{V}\right)
\end{aligned}
$$

where $C_{t}$ is the aerosol concentration at time $t, C_{0}$ is the initial aerosol concentration, and $\lambda$ is the overall decay rate, $t$ is the time, $\lambda_{d}$ is the deposition rate, $\lambda_{a}$ is the air exchange rate, $A$ is the surface area and $V$ is the volume, including the area and volume of the chamber and the measuring instruments present inside the chamber (Byrne et al., 1995). The combined decay rate $\lambda$ was calculated from the slope of the aerosol concentration decay curve (natural log scale vs. time). The deposition rate $\lambda_{d}$ was isolated by subtracting the air exchange rate $\lambda_{a}$ using Eq. (2). The deposition rate $\lambda_{d}$ was converted into a deposition velocity $V_{d}$ using Eq. (3).

The ELPI produced charge data for every minute using a method from Matthews et al. (2011) and Glover and Chan (2004) whereby the instrument's corona unit was turned on and off at 30 -second intervals, so that the instrument recorded both mean current and aerosol concentration, and used these values to calculate particle charge (in elementary charge unit $e$ ); the charge distribution of aerosols in the chamber over a period of 30 minutes and the mean charge was determined. Fig. 2 shows the charge on $0.5 \mu \mathrm{m}, 1.0 \mu \mathrm{m}$, and $2.0 \mu \mathrm{m}$ particles inside the chamber for both polarities. In both cases, the charge can be seen diminishing over time in the chamber and this can easily be explained by the fact that aerosols interact with ions present in the air which alters their charge distribution (Aplin and Harrison, 1999). The decline in charge over time can also be attributed to the observation from previous studies that higher-charged aerosols deposit more quickly than lower-charged aerosols (Stein $e t$ al., 1973; McMurry and Rader, 1985). Additionally, it can be seen from Fig. 2 that larger-sized aerosols, due to their larger surface area, have a tendency to hold a higher charge, as compared with smaller-sized aerosols. Furthermore, it is important to note that while the UDAC could deposit a large positive or large negative charge on aerosols in each run, the magnitude of the maximum charge was not fully reproducible between runs. The net charge measured on ambient air in the chamber (and in the laboratory air that could enter the chamber via infiltration) was in the range of +7.20-10.33e.

The experimental procedure involved establishing a suitable aerosol concentration inside the chamber, after which the nebulizer and delivery air was disengaged; in all runs, the aerosol concentration was maintained below $3 \times$ $10^{3}$ particles $\mathrm{cm}^{-3}$, so as to minimize coagulation (Hussein et al., 2009a). After the injection period, particles were allowed to settle over a 30-minutes interval, and the APS and ELPI instruments monitored particle concentration and charge variations. Infiltrated ambient air, as a result of air exchange, had a typical particle concentration of $0.2-0.9$ particle $\mathrm{cm}^{-3}$, which was 30-100 times lower than the monodisperse aerosol concentration injected into the chamber.

Aerosol deposition measurements were made with three interior wall surface types separately present in the chamber: aluminum, wallpaper, and polyethylene sheet were used because of their resemblance to surfaces present indoors. The latter two surfaces were mounted onto the aluminum chamber walls for individual experimental runs, polyethylene sheet was attached to the walls of the chamber and all measurements were made without removing it. The charge on the surface of the polyethylene sheet was monitored continuously, so as to detect any effect of triboelectric charging during sheet installation and any subsequent changes; no such variation was observed.

Fig. 3 shows the matrix of experimental runs carried out, with the following naming scheme used: $\mathrm{H}-\mathrm{Alu}-(\mathrm{C}+)-0.5$ means high airflow $(H)$, aluminum surface (alu), positive corona polarity $(C+)$, and $0.5 \mu \mathrm{m}$ particle size $(0.5)$. There were four sets of experiment: three with different chamber surfaces (aluminum, wallpaper, and polyethylene) and the higher fan speed, while a fourth one focused on an aluminum chamber surface only, with a lower fan speed. Additionally, two more sets of experiments were conducted, one at each of the two fan speeds but without the corona unit operating,

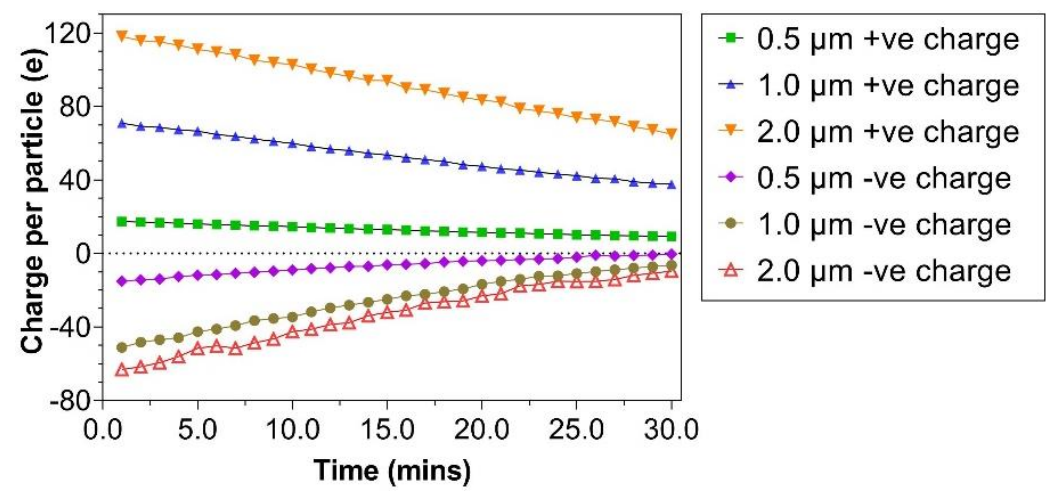

Fig. 2. Observed aerosol charge depletion over 30 minutes in the test chamber. 


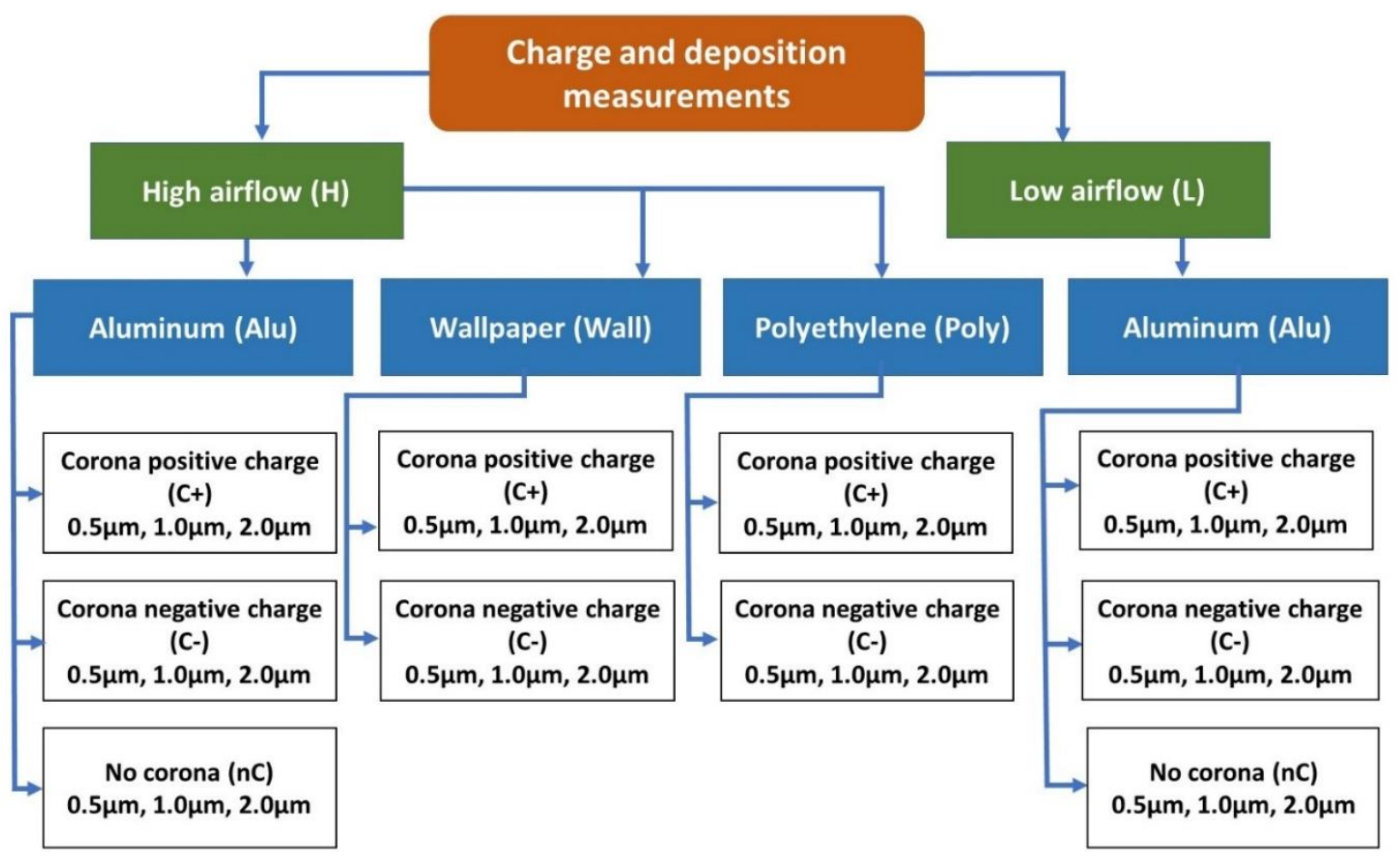

Fig. 3. Flow chart showing matrix of experimental parameters investigated.

so as to measure the charge and deposition velocity of aerosols without charge enhancement; this would be used for comparative purposes. Three replicate tests were conducted for each combination of polarity, particle size, and surface type, representing a total of more than 90 individual runs. The temperature and humidity was also measured during the tests both inside and outside the chamber (inside the laboratory); the temperature and humidity ranges recorded inside the chamber were $23 \pm 2^{\circ} \mathrm{C}$ and $40 \pm 8 \%$, respectively, and outside the chamber were $20 \pm 2{ }^{\circ} \mathrm{C}$ and $44 \pm 9 \%$, respectively. The surface potential on the chamber surfaces was measured using a static meter (Model 715; Fraser Ltd, Devon, UK). The measured surface potentials on aluminum and wallpaper were both $+0.01-0.03 \mathrm{kV}$, respectively; the surface potential was measured at different points on the chamber surfaces and it was found that on wallpaper, the surface potential showed small fluctuations only. However, a larger range of surface potentials was observed on the polyethylene surface: -0.3 to $-1.2 \mathrm{kV}$.

\section{Data Analysis}

Aerosol deposition data from each 30-minutes measurement was divided into six 5-minutes data sections, and deposition velocity and mean charge was measured for each of these intervals. Statistical analysis of the data was carried using SPSS Statistics 14 (IBM Corp., Armonk, NY, USA). All datasets were analyzed for normality and variance. All datasets had homogeneous variances, and although most of the sets were normally distributed, some deviated from this behavior, and hence a Mann-Whitney $U$ test was applied to examine the statistically significant difference between datasets.

Box-and-whisker plots are used to depict trends in the measurements. The approach taken to constructing these plots took account of the fact that the maximum positive or negative charge deposited on particles by the UDAC was not constant between individual trials, and bins were thus defined that represented an approximately equal division between upper and lower charge values for each polarity.

\section{RESULTS}

\section{Deposition Velocity Analysis for Different Charge Levels and Polarities under High Airflow Conditions on Aluminum Surface}

Table 1 summarizes the entire dataset upon which statistical comparisons were made. For $0.5 \mu \mathrm{m}$ particles, the analysis indicates that $\mathrm{C}+$ and $\mathrm{C}-$ deposition velocities are not statistically different $(\mathrm{p}=0.308)$, but a comparison between $\mathrm{C}+$ and $\mathrm{nC}$ indicates a significant difference $(\mathrm{p}<0.001)$, with $\mathrm{C}+$ being higher than $\mathrm{nC}$ by $72 \%$. For the $1.0 \mu \mathrm{m}$ particles, a similar observation is made, with a $\mathrm{C}+/ \mathrm{C}-$ comparison showing $\mathrm{p}=0.279$ (not significant) but a $\mathrm{C}+/ \mathrm{nC}$ comparison indicating a significant difference $(\mathrm{p}<0.013)$, with $\mathrm{C}+$ being higher than $\mathrm{nC}$ by $37 \%$. For the $2.0 \mu \mathrm{m}$ the increasing influence of gravitational effects, relative to charge effects, are demonstrated, the $\mathrm{C}+/ \mathrm{C}-$ comparison again showing no significant difference $(\mathrm{p}=0.988)$ but the $\mathrm{C}+$ and $\mathrm{nC}$ values (although significantly different; $\mathrm{p}<0.002$ ), being different by only $27 \%$.

To elucidate the statistical findings shown in Table 1, box plots of deposition velocity data are shown in Fig. 4, with charge bins representing positive polarity $(\mathrm{C}+)$, negative polarity $(\mathrm{C}-)$, and uncharged $(\mathrm{nC})$ aerosol charge regimes. In Figs. 4(a), 4(b), and 4(c), data generated under high airflow $(\mathrm{H})$ conditions are presented for $0.5 \mu \mathrm{m}, 1.0 \mu \mathrm{m}$, and $2.0 \mu \mathrm{m}$ aerosols, respectively. In Fig. 4(d), deposition data for 
Table 1. Mean (and standard deviation [SD]) deposition velocity values, for tests involving aerosols with high positive charge $(\mathrm{C}+)$, high negative charge $(\mathrm{C}-)$, and uncharged status $(\mathrm{nC})$, and for each of three particle size distributions. Values in the reference column are statistically compared with values in the same row, and p-values are presented in bold type for statistically significant cases. Percentage differences are shown between $\mathrm{nC}$ and $\mathrm{C}+$ cases for each particle size. High airflow (H) and low airflow (L) data are presented.

\begin{tabular}{|c|c|c|c|c|c|c|}
\hline & $\begin{array}{l}\text { H-alu- }(\mathrm{C}+) \\
\text { (reference column) }\end{array}$ & H-alu-(C-) & H-alu-(nC) & $\begin{array}{l}\mathrm{L}-\text { alu- }(\mathrm{C}+) \\
\text { (reference column) }\end{array}$ & L-alu-(C-) & L-alu-(nC) \\
\hline $\begin{array}{l}\text { Aerosol } \\
\text { size } \\
(\mu \mathrm{m})\end{array}$ & $\begin{array}{l}\text { Deposition } \\
\text { velocity mean } \\
\text { and } \mathrm{SD} \\
\left(\times 10^{-5} \mathrm{~m} \mathrm{~s}^{-1}\right)\end{array}$ & $\begin{array}{l}\text { Deposition } \\
\text { velocity mean } \\
\text { and SD } \\
\left(\times 10^{-5} \mathrm{~m} \mathrm{~s}^{-1}\right)\end{array}$ & $\begin{array}{l}\text { Deposition } \\
\text { velocity mean } \\
\text { and } \mathrm{SD} \\
\left(\times 10^{-5} \mathrm{~m} \mathrm{~s}^{-1}\right)\end{array}$ & $\begin{array}{l}\text { Deposition } \\
\text { velocity mean } \\
\text { and } \mathrm{SD} \\
\left(\times 10^{-5} \mathrm{~m} \mathrm{~s}^{-1}\right)\end{array}$ & $\begin{array}{l}\text { Deposition } \\
\text { velocity mean } \\
\text { and SD } \\
\left(\times 10^{-5} \mathrm{~m} \mathrm{~s}^{-1}\right)\end{array}$ & $\begin{array}{l}\text { Deposition } \\
\text { velocity mean } \\
\text { and } \mathrm{SD} \\
\left(\times 10^{-5} \mathrm{~m} \mathrm{~s}^{-1}\right)\end{array}$ \\
\hline 0.5 & $4.28 \pm 1.72$ & $\begin{array}{l}4.86 \pm 1.32 \\
(p=0.308)\end{array}$ & $\begin{array}{l}1.19 \pm 1.01 \\
(\mathbf{p}<\mathbf{0 . 0 0 1}) \\
72 \%\end{array}$ & $3.92 \pm 1.80$ & $\begin{array}{l}4.37 \pm 1.30 \\
(p=0.401)\end{array}$ & $\begin{array}{l}1.47 \pm 1.05 \\
(\mathbf{p}<\mathbf{0 . 0 0 1}) \\
62 \%\end{array}$ \\
\hline 1.0 & $5.46 \pm 1.61$ & $\begin{array}{l}6.01 \pm 1.58 \\
(p=0.279)\end{array}$ & $\begin{array}{l}3.46 \pm 1.77 \\
(\mathbf{p}<\mathbf{0 . 0 1 3}) \\
37 \%\end{array}$ & $5.81 \pm 2.00$ & $\begin{array}{l}6.71 \pm 1.80 \\
(p=0.104)\end{array}$ & $\begin{array}{l}3.97 \pm 1.33 \\
(\mathbf{p}<\mathbf{0 . 0 0 7}) \\
32 \%\end{array}$ \\
\hline 2.0 & $10.52 \pm 1.89$ & $\begin{array}{l}10.91 \pm 2.36 \\
(p=0.988)\end{array}$ & $\begin{array}{l}7.64 \pm 3.04 \\
(\mathbf{p}<\mathbf{0 . 0 0 2}) \\
27 \%\end{array}$ & $10.14 \pm 1.43$ & $\begin{array}{l}11.23 \pm 1.89 \\
(p=0.067)\end{array}$ & $\begin{array}{l}7.78 \pm 2.23 \\
(\mathbf{p}<\mathbf{0 . 0 0 1}) \\
23 \%\end{array}$ \\
\hline
\end{tabular}
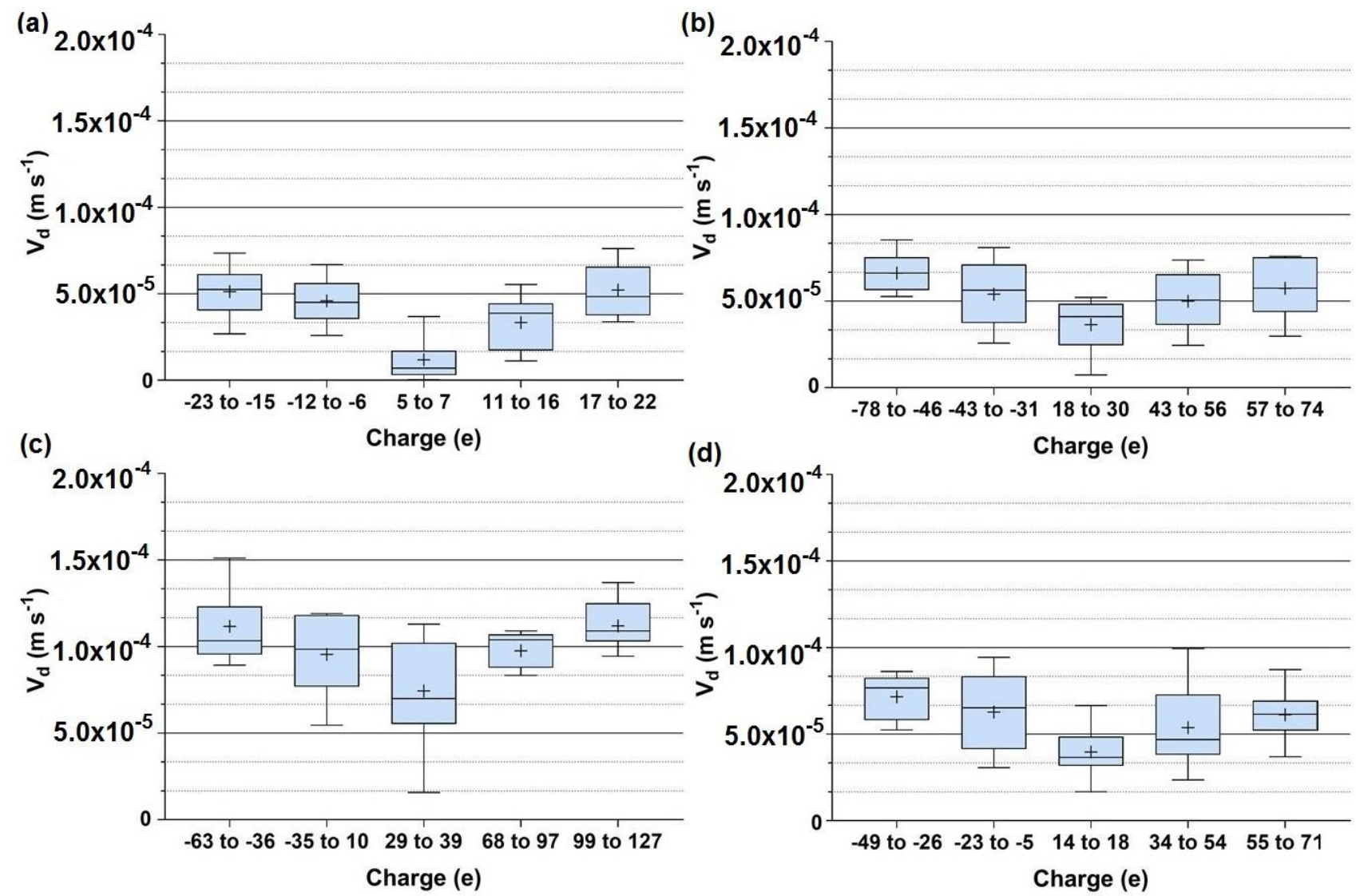

Fig. 4. Box-and-whisker plots, depicting comparative deposition velocity values for charged positive $(\mathrm{C}+)$ and negative $(\mathrm{C}-)$, and no-corona-charge (nC) aerosols. Data are shown for (a) $0.5 \mu \mathrm{m}$ aerosols under high airflow, (b) $1.0 \mu \mathrm{m}$ aerosols under high airflow, (c) $2.0 \mu \mathrm{m}$ aerosols under high airflow, and (d) $1.0 \mu \mathrm{m}$ aerosols under low airflow. For each charge polarity, the range of observed charges is divided across two bins.

$1.0 \mu \mathrm{m}$ particles under low airflow (L) conditions are shown. To reflect the range of charges measured in each run and the different initial charge values (explained in the methodology section, and depicted in Fig. 2), two charge bins are used to represent each of $\mathrm{C}+$ and $\mathrm{C}$ - cases in Figs. 4(a)-4(d), with a single charge bin being used to represent $\mathrm{nC}$ (as only minor 
charge changes were seen over the course of these runs), the cases where the corona charger was not operating. For $0.5 \mu \mathrm{m}$ aerosols (Fig. 4(a), C-corresponds to charge bins of $-23 \mathrm{e}$ to $-15 \mathrm{e}$ and $-12 \mathrm{e}$ to $-6 \mathrm{e}, \mathrm{nC}$ is $+5-7 \mathrm{e}$, and $\mathrm{C}+$ is $+11-16 \mathrm{e}$ and $+17-22 \mathrm{e}$ (the charge was measured in elementary charge unit). For $1.0 \mu \mathrm{m}$ data, shown in Fig. 4(b), the corona unit imparts greater magnitudes of charge on these larger particles, and $\mathrm{C}-$ corresponds to charge bins of $-78 \mathrm{e}$ to $-46 \mathrm{e}$ and $-43 \mathrm{e}$ to $-31 \mathrm{e}, \mathrm{nC}$ is $+18-30 \mathrm{e}$, and $\mathrm{C}+$ is $+43-56 \mathrm{e}$ and $+57-74 \mathrm{e}$.

The general trend that can be seen from Figs. 4(a)-4(d) is that both $\mathrm{C}+$ and $\mathrm{C}-$ aerosols exhibit a higher deposition velocity than $\mathrm{nC}$ aerosols; this trend is followed for both mean and median values.

\section{Deposition Velocity Analysis for Different Charge Levels and Polarities under Low Airflow Conditions on an Aluminum Surface}

The right-hand columns in Table 1 summarize the data generated under low airflow conditions in the test chamber. For these conditions, statistical differences between $\mathrm{C}+$ and $\mathrm{C}$ - values were not observed for any of the three particle sizes investigated, but for $\mathrm{C}+$ and $\mathrm{nC}$ comparisons, differences of $\mathrm{p}<$ $0.001, \mathrm{p}<0.007$, and $\mathrm{p}<0.001$ were found for $0.5 \mu \mathrm{m}, 1.0 \mu \mathrm{m}$, and $2.0 \mu \mathrm{m}$ particle sizes, respectively. The corresponding percentage differences between $\mathrm{C}+$ and $\mathrm{nC}$ were $62 \%, 27 \%$, and $23 \%$ for the three particle sizes, respectively.

To elucidate the statistical findings by showing data trends, Fig. 4(d) shows a box plot for $1.0 \mu \mathrm{m}$ aerosol deposition velocities measured under low airflow conditions. The overall trends are similar to those shown in Figs. 4(a)-4(c) for high airflow, with the $\mathrm{nC}$ particles (in this case, with charges in the bin of $+14-18 \mathrm{e}$ ) exhibiting lower deposition velocities than $\mathrm{C}+$ or $\mathrm{C}-$ cases.

\section{Comparison of Charged Aerosol Deposition Velocity Values among Different Surfaces}

The effect of chamber wall surface type on deposition of charged aerosols was investigated by conducting tests whereby wallpaper and polyethylene sheet were attached to the chamber walls in separate runs. Mean deposition velocities (and standard deviations) for aerosols depositing on wallpaper and polyethylene surfaces are shown in Table 2. Statistically, p-values for comparison of datasets representing aerosols with opposite polarities were not significant $(\mathrm{p}=0.091, \mathrm{p}=$ 0.118 , and $p=0.963$ for wallpaper and $p=0.134, p=0.696$, and $\mathrm{p}=0.839$ for polyethylene for the aerosol sizes $0.5 \mu \mathrm{m}$, $1.0 \mu \mathrm{m}$, and $2.0 \mu \mathrm{m}$, respectively). Therefore, only the positive polarity data $(\mathrm{C}+)$ is displayed in Fig. 5, which is a box plot intended to elucidate the data trends for the three particle sizes, and a log scale is used so that trends can be more easily distinguished.

The overall trend observable in Fig. 5 is that the deposition velocity increased with increment in charge and this is consistent regardless of particle size and surface type.

Table 2. Mean deposition velocities (and standard deviation [SD]) of $0.5 \mu \mathrm{m}, 1.0 \mu \mathrm{m}$, and $2.0 \mu \mathrm{m}$ aerosols in the presence of wallpaper and polyethylene surfaces.

\begin{tabular}{lll}
\hline & H-wall- $(\mathrm{C}+)$ & H-poly- $(\mathrm{C}+)$ \\
\cline { 2 - 3 } Aerosol Size $(\mu \mathrm{m})$ & Deposition velocity mean and SD $\left(\times 10^{-5} \mathrm{~m} \mathrm{~s}^{-1}\right)$ & Deposition velocity mean and SD $\left(\times 10^{-5} \mathrm{~m} \mathrm{~s}^{-1}\right)$ \\
\hline 0.5 & $4.67 \pm 2.23$ & $37.21 \pm 7.20$ \\
1.0 & $7.81 \pm 2.54$ & $39.83 \pm 8.78$ \\
2.0 & $13.24 \pm 2.79$ & $49.42 \pm 17.11$ \\
\hline
\end{tabular}
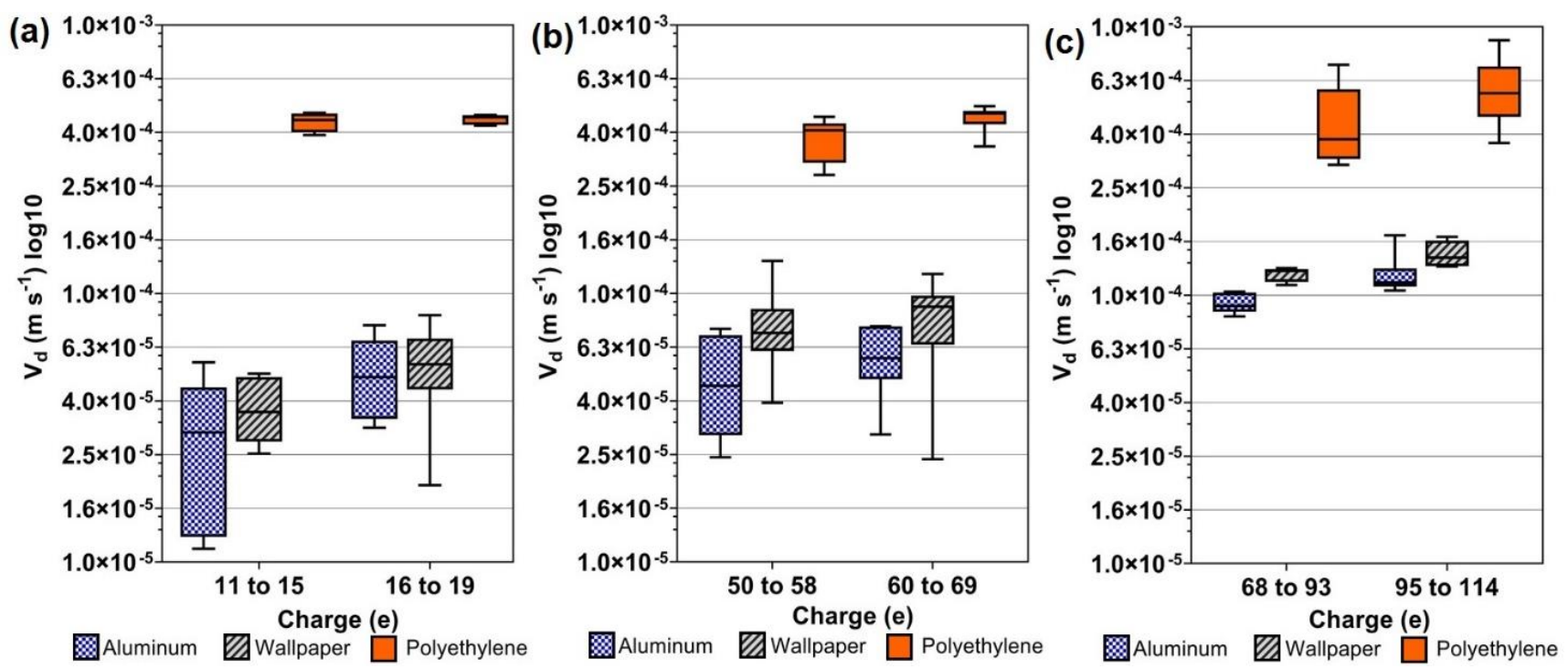

Fig. 5. Box-and-whisker plots, depicting comparative deposition velocity values for charged positive (C+) and no-coronacharge (nC) aerosols. Data are shown for (a) $0.5 \mu \mathrm{m}$ aerosols, (b) $1.0 \mu \mathrm{m}$ aerosols, and (c) $2.0 \mu \mathrm{m}$ aerosols, and deposition on aluminum, wallpaper, and polyethylene sheet is shown in each of (a), (b), and (c). 
Deposition velocities on wallpaper and aluminum surfaces are comparable, but deposition velocities in the polyethylenelined chamber are considerably higher, and this is the case for all three particle sizes. It can also be observed that the percentage difference in deposition velocity decreases with increases in aerosol size, as seen in Figs. 5(a)-5(c).

\section{DISCUSSION}

The main purpose of this study was to investigate the effect of charge on the deposition of radioactive aerosols indoors. The self-charging process makes radioactive aerosols unique as compared to ambient aerosols, where charge is generally assumed to be neutralized or very low (single elementary unit) due to aerosol interaction with the ions present in the air (Jayaratne et al., 2014) and charge on ambient indoor aerosols is found to be lower than charge on outdoor aerosols (J-Fatokun et al., 2008). In this study, through use of a corona charger, the aerosols were given a charge in a range representative of radioactive aerosols (Kim et al., 2015). This aerosol charge introduces an electrostatic interaction with other aerosols, and also with surfaces present in the surroundings (Filippov, 1992; Wistrom and Khachatourian, 2001).

Through a review of the literature a knowledge gap was identified regarding the detailed investigation of charged aerosol deposition indoors, so that existing studies that had limited relevance to the current understanding of indoor behavior of radioactive aerosols could benefit. To redress this, a test chamber study of aerosol deposition was carried out with particle sizes, aerosol charge (magnitude and polarity), airflow, and chamber interior wall type being the parameters under investigation.

As shown in Fig. 4 and Table 1, the deposition velocity of corona-charged aerosols is significantly higher, for all particle sizes, than that of aerosols which do not carry corona-enhanced charges, and this is consistent with other findings (McMurry and Rader, 1985; Shimada et al., 1989). The electric mobility of aerosols depends on their properties such as diameter and density and is independent of electric field; aerosols showing high electric mobility obtain high terminal velocity in an electric field (Schery, 2001). It was observed that the difference was greater for $0.5 \mu \mathrm{m}$ particles than for $1.0 \mu \mathrm{m}$ or $2.0 \mu \mathrm{m}$ particles, and this is attributable to the smaller particles being more strongly influenced by electrostatic and Brownian diffusion effects, and less so by the gravitational forces that are dominant for larger particles (Nazaroff, 2004). As shown in Figs. 4(a)-4(c) the gap between $\mathrm{H}$-alu- $(\mathrm{C}+)$ and $\mathrm{H}$-alu-(nC) decreases with increase in aerosol size: $72 \%, 37 \%$, and $27 \%$ for $0.5 \mu \mathrm{m}, 1.0 \mu \mathrm{m}$, and $2.0 \mu \mathrm{m}$ aerosols, respectively. Data presented in Figs. 4(a)-4(c) shows that with increase in size of aerosols $(0.5-2.0 \mu \mathrm{m})$ the deposition velocity is increasing; mean deposition velocities of different aerosol sizes can be seen increasing with increase in size of the aerosols in Table 1. However, it can be noted in particular relation to the present work that the effects of electric mobility on deposition of larger aerosols is less significant, because gravitational effects are dominant. This may explain the unexpected observation of small differences in deposition velocity between charged and uncharged aerosols. For low airflow, L-alu-(C+) compared with L-alu-(nC), a similar trend is observed, but the decrease in percentage difference as particle size increases is more gradual: $62 \%, 32 \%$, and $23 \%$ for $0.5 \mu \mathrm{m}, 1.0 \mu \mathrm{m}$, and $2.0 \mu \mathrm{m}$ aerosols, respectively. This can be explained if it is considered that inertial impaction and turbulence effects, which contribute to the deposition of larger particles (Chiou et al., 2011), are more pronounced for higher chamber airflow cases.

Despite the trends described above, an overall observation was made that there was no significant difference between deposition velocities, for a given aerosol size and charge, under both airflow conditions; although different at the center of the chamber, the air velocity close to the chamber walls was comparable: $0.085 \mathrm{~m} \mathrm{~s}^{-1}$ in the high airflow case and $0.023 \mathrm{~m} \mathrm{~s}^{-1}$ in the low airflow case. This may result in the effect of airflow near the wall surfaces, compared with electrostatic effects, being minor, as observed elsewhere (Chen and Lai, 2004).

Deposition velocity measurements were separately made with aerosols of both charge polarities, but no significant differences associated with polarity were observed. There are a number of reasons that can explain this observation, one of which is that, due to the nature of corona charging, the magnitude of $\mathrm{C}+$ and $\mathrm{C}$ - charges were not completely matched; for example, in the case of $0.5 \mu \mathrm{m}$ particles depositing on aluminum under the high airflow regime, $\mathrm{C}+$ was $+17.25 \mathrm{e}$ and $\mathrm{C}-$ was $-14.15 \mathrm{e}$. The impact of image charges in the chamber may also be important (Tinkle and Barlow, 2001), and additionally, variations in aerosol concentrations may be a confounding factor (Mayya et al., 2004).

Corona-charged aerosol deposition experiments were performed with different interior chamber surfaces, to account for the fact that a wide variety of surfaces are present in the indoor environment. Experiments for both positive and negative aerosol polarity were separately performed, and the surfaces selected were aluminum, wallpaper, and polyethylene. Aluminum was selected as it is a conducting surface, and hence suitable for comparing the effects of opposite aerosol polarity. Wallpaper and polyethylene are non-conductors and have islands of both positive and negative charges (Lungu, 2004), making comparison difficult, but they are nevertheless representative of real indoor surfaces. As measured with a static meter, the dominant charge polarity on the wallpaper surface was positive, and the dominant charge polarity on the polyethylene surface was negative, but the presence of islands of both positive and negative charge, in particular, on the polyethylene surface may explain why a significant difference in deposition velocity is not seen between positive and negative particles depositing on this surface.

In this work, it was found that corona-charged aerosols of both polarities exhibited greater deposition velocity on a given surface, for all particle sizes, when compared with aerosols that did not carry enhanced charges. A small, but not statistically significant, difference in mean aerosol deposition velocity on wallpaper compared with aluminum was observed, and this is attributable to surface roughness (Hussein et al., 2009b). A striking difference, typically of a factor of 4-8 in 
deposition velocity between surfaces is observed when aerosol deposition on aluminum and wallpaper is compared with deposition on polyethylene, due to stronger associated electric field, resulting in aerosols having greater deposition. The attractive effect of plastic as an aerosol deposition surface was also observed by Wu et al. (2006) who studied aerosol removal due to negative ions in the presence of different surfaces such as steel, wood, wallpaper, and polyvinyl chloride (PVC). Additionally, Lai (2006) investigated the enhanced deposition of aerosols (with Boltzmann charge equilibrium) on different surfaces with and without antistatic charge treatment and found that deposition was enhanced by $93 \%$ on an untreated acetate surface. Unlike the current study, however, the charged status of the aerosols was not explicitly characterized.

The motivation for the current study was to better understand the mechanisms of charged aerosol deposition, so that this knowledge could be applied in the context of ingress of radioactive aerosols, which is inherently electrically charged, resulting from nuclear accidents; indoor deposition velocity data for charged aerosols are, to date, limited. The present work has demonstrated that the deposition of aerosols that are carrying charges representative of radionuclides can be enhanced by up to $72 \%$ due to the presence of the charge. This finding signals a need for updating aerosol deposition data that are used for parameterizing nuclear risk assessment models.

This study not only enhances current understanding of radioactive aerosol deposition but also has relevance to the other applications which exploit aerosol charging as a means of increasing aerosol deposition rates, e.g., ionizers used domestically and commercially for indoor air quality control (Grabarczyk, 2001; Chan and Cheng, 2006).

\section{CONCLUSIONS}

Exposure to radioactive aerosols released by accident may pose a significant risk to human health, which cannot be accurately evaluated without understanding the effect of ionization (self-charging) on particle deposition. Hence, the current study aimed to fill this knowledge gap by conducting detailed deposition measurements in a test chamber. It was discovered that charging the particles significantly enhanced their deposition velocity, with the largest increase occurring for the smallest tested size fraction $(0.5 \mu \mathrm{m}$ in diameter $)$. Additionally, lining the interior walls of the chamber with a material possessing a high surface potential, such as polyethylene, instead of a low one, such as wallpaper, promoted deposition. Our deposition data can be used to update nuclear accident risk assessment models as well to develop inhalation exposure risk reduction strategies for indoor radioactive aerosols, particularly with isotopes such as ${ }^{131} \mathrm{I}$, which are concentrated in the sub-micrometer fraction.

\section{ACKNOWLEDGMENTS}

A special thanks to Cambustion Ltd, United Kingdom, for kindly loaning the UDAC corona charger to NUI Galway for this study and to the College of Science and Engineering,
NUI Galway, for funding the Ph.D. studies of the lead author via a postgraduate fellowship. The authors are grateful to Prof. John Newell, NUI Galway, for statistical advice.

\section{REFERENCES}

Abadie, M., Limam, K. and Allard, F. (2001). Indoor particle pollution: Effect of wall textures on particle deposition. Build. Environ. 36: 821-827. https://doi.org/1 0.1016/S0360-1323(01)00007-5

Acar, H., Çakabay, B., Bayrak, F. and Evrenkaya, T. (2011). Effects of the chernobyl disaster on thyroid cancer incidence in turkey after 22 years. Int. Sch. Res. Not. 2011: 257943. https://doi.org/10.5402/2011/257943

Andersson, K.G., Roed, J., Byrne, M.A. and Hession, H. (2006). Deposition of contaminant aerosol on human skin. J. Environ. Radioact. 85: 182-195. https://doi.org/1 0.1016/j.jenvrad.2004.04.016

Aplin, K.L. and Harrison, R.G. (1999). The interaction between air ions and aerosol particles in the atmosphere. Int. Phys. Conf. Ser. 163: 28-31. https://arxiv.org/abs/120 $9.4549 \mathrm{v} 1$

Bauman, D., Arens, F., Ernest Bauman, D.F., Member ASHRAE Arens, P.E. and Ashrae, M. (1991). The prediction of indoor air motion for occupant cooling in naturally ventilated buildings. ASHRAE Tran. 97 Part 1. https://escholarship.org/uc/item/3qt2h9xv

Berry, D., Mainelis, G. and Fennell, D. (2007). Effect of an ionic air cleaner on indoor/outdoor particle ratios in a residential environment. Aerosol Sci. Technol. 41: 315328. https://doi.org/10.1080/02786820701199702

Byrne, M.A., Goddard, A.J.H., Lange, C. and Roed, J. (1995). Stable tracer aerosol deposition measurements in a test chamber. J. Aerosol Sci. 26: 645-653. https://doi.org/10.1 016/0021-8502(95)00003-U

Chan, M.Y. and Cheng, B.N. (2006). Performance evaluation of domestic ionizer type air cleaners. Archit. Sci. Rev. 49: 357-362. https://doi.org/10.3763/asre.2006.4946

Chen, C. and Zhao, B. (2011). Review of relationship between indoor and outdoor particles: I/O ratio, infiltration factor and penetration factor. Atmos. Environ. 45: 275-288. https://doi.org/10.1016/j.atmosenv.2010.09.048

Chen, F. and Lai, A.C.K. (2004). An eulerian model for particle deposition under electrostatic and turbulent conditions. J. Aerosol Sci. 35: 47-62. https://doi.org/10.1 016/s0021-8502(03)00383-5

Chiou, M.C., Chiu, C.H. and Chen, H.S. (2011). Particle deposition with thermal and electrical effects in turbulent flows. Int. J. Therm. Sci. 50: 1867-1877. https://doi.org/1 $0.1016 /$ j.ijthermalsci.2011.03.013

Clement, C.F. and Harrison, R.G. (2000). Enhanced localised charging of radioactive aerosols. J. Aerosol Sci. 31: 363378. https://doi.org/10.1016/s0021-8502(99)00064-6

Cooper, D.W., Peters, M.H. and Miller, R.J. (1989). Predicted deposition of submicrometer particles due to diffusion and electrostatics in viscous axisymmetric stagnation-point flow. Aerosol Sci. Technol. 11: 133-143. https://doi.org/10.1080/02786828908959306

Cuddihy, R.G., Finch, G.L., Newton, G.J., Hahn, F.F., 
Mewhinney, J.A., Rothenberg, S.J. and Powers, D.A. (1989). Characteristics of radioactive particles released from the chernobyl nuclear reactor. Environ. Sci. Technol. 23: 89-95. https://doi.org/10.1021/es00178a011

Dorrian, M.D. (1997). Particle size distributions of radioactive aerosols in the environment. Radiat. Prot. Dosim. 69: 117-132. https://doi.org/10.1093/oxfordjourn als.rpd.a031892

El Hamdani, S., Limam, K., Abadie, M.O. and Bendou, A. (2008). Deposition of fine particles on building internal surfaces. Atmos. Environ. 42: 8893-8901. https://doi.org/ 10.1016/j.atmosenv.2008.09.005

Filippov, A.V. (1992). Electrostatic deposition of a moving charged aerosol cloud onto a conducting sphere. $J$. Aerosol Sci. 23: 203-215. https://doi.org/10.1016/00218502(92)90323-n

Fogh, C.L. and Andersson, K.G. (2000). Modelling of skin exposure from distributed sources. Ann. Occup. Hyg. 44: 529-532. https://doi.org/10.1016/s0003-4878(00)00035-1

Gensdarmes, F., Boulaud, D. and Renoux, A. (2001). Electrical charging of radioactive aerosols - comparison of the clement-harrison models with new experiments. $J$. Aerosol Sci. 32: 1437-1458. https://doi.org/10.1016/s00 21-8502(01)00065-9

Glover, W. and Chan, H.K. (2004). Electrostatic charge characterization of pharmaceutical aerosols using electrical low-pressure impaction (ELPI). J. Aerosol Sci. 35: 755764. https://doi.org/10.1016/j.jaerosci.2003.12.003

Gong, N., Tham, K.W., Melikov, A.K., Wyon, D.P., Sekhar, S.C. and Cheong, K.W. (2006). The acceptable air velocity range for local air movement in the tropics. HVAC\&R Res. 12: 1065-1076. https://doi.org/10.1080/1 0789669.2006.10391451

Grabarczyk, Z. (2001). Effectiveness of indoor air cleaning with corona ionizers. J. Electrostat. 51-52: 278-283. https://doi.org/10.1016/s0304-3886(01)00058-4

Hinds, W.C. (1999). Aerosol technology: Properties, behaviour, and measurement of airborne particles. John Wiley \& Sons.

Homoki, Z., Déri, Z., Fülöp, N., Kelemen, M., Kónyi, J.K., Laca, É.O., Szabó, G., Ugron, Á. and Turai, I. (2013). Assessment of environmental radiation monitoring data in Hungary following the Fukushima accident. Radioprotection 48: S117-S123. https://doi.org/10.1051/ radiopro/20139918

Hussein, T., Hruška, A., Dohányosová, P., Džumbová, L., Hemerka, J., Kulmala, M. and Smolík, J. (2009a). Deposition rates on smooth surfaces and coagulation of aerosol particles inside a test chamber. Atmos. Environ. 43: 905-914. https://doi.org/10.1016/j.atmosenv.2008.1 0.059

Hussein, T., Kubincová, L., Džumbová, L., Hruška, A., Dohányosová, P., Hemerka, J. and Smolík, J. (2009b). Deposition of aerosol particles on rough surfaces inside a test chamber. Build. Environ. 44: 2056-2063. https://doi.org/10.1016/j.buildenv.2009.02.009

Ishikawa, T., Sorimachi, A., Arae, H., Sahoo, S.K., Janik, M., Hosoda, M. and Tokonami, S. (2014). Simultaneous sampling of indoor and outdoor airborne radioactivity after the Fukushima Daiichi nuclear power plant accident. Environ. Sci. Technol. 48: 2430-2435. https://doi.org/10. 1021/es404691m

Jayaratne, E.R., Ling, X. and Morawska, L. (2014). Observation of ions and particles near busy roads using a neutral cluster and air ion spectrometer (NAIS). Atmos. Environ. 84: 198-203. https://doi.org/10.1016/j.atmosenv. 2013.11.045

J-Fatokun, F.O., Morawska, L., Jamriska, M. and Jayaratne, E.R. (2008). Application of aerosol electrometer for ambient particle charge measurements. Atmos. Environ. 42: 88278830. https://doi.org/10.1016/j.atmosenv.2008.08.025

Kameník, J., Dulaiova, H., Buesseler, K.O., Pike, S.M. and Št'astná, K. (2013). Cesium-134 and 137 activities in the central North Pacific Ocean after the Fukushima Dai-ichi Nuclear Power Plant accident. Biogeosciences 10: 60456052. https://doi.org/10.5194/bg-10-6045-2013

Kannan, V., Iyengar, M.A.R. and Ramesh, R. (2001). Dose estimates to the public from ${ }^{210} \mathrm{Po}$ ingestion via dietary sources at Kalpakkam (India). Appl. Radiat. Isot. 54: 663674. https://doi.org/10.1016/S0969-8043(00)00301-8

Kim, J.J., Hann, T. and Lee, S.J. (2019). Effect of flow and humidity on indoor deposition of particulate matter. Environ. Pollut. 255: 113263. https://doi.org/10.1016/j.e nvpol.2019.113263

Kim, Y.H., Yiacoumi, S., Lee, I., McFarlane, J. and Tsouris, C. (2014). Influence of radioactivity on surface charging and aggregation kinetics of particles in the atmosphere. Environ. Sci. Technol. 48: 182-189. https://doi.org/10.10 21/es4047439

Kim, Y.H., Yiacoumi, S. and Tsouris, C. (2015). Surface charge accumulation of particles containing radionuclides in open air. J. Environ. Radioact. 143: 91-99. https://doi.org/10.1016/j.jenvrad.2015.02.017

Kulmala, M., Asmi, A. and Pirjola, L. (1999). Indoor air aerosol model: The effect of outdoor air, filtration and ventilation on indoor concentrations. Atmos. Environ. 33: 21332144. https://doi.org/10.1016/s1352-2310(99)00070-9

Kweon, H., Yiacoumi, S., Lee, I., McFarlane, J. and Tsouris, C. (2013). Influence of surface potential on the adhesive force of radioactive gold surfaces. Langmuir 29: 1187611883. https://doi.org/10.1021/la4008476

Lai, A.C.K. (2006). Investigation of electrostatic forces on particle deposition in a test chamber. Indoor Built Environ. 15: 179-186. https://doi.org/10.1177/1420326x06063219

Lee, H. and Yook, S.J. (2014). Deposition velocity of particles in charge equilibrium onto a flat plate in parallel airflow under the influence of simultaneous electrophoresis and thermophoresis. J. Aerosol Sci. 67: 166-176. https://doi.org/10.1016/j.jaerosci.2013.10.006

Lee, S.H. and Rasaiah, J.C. (1994). Molecular dynamics simulation of ionic mobility. I. Alkali metal cations in water at $25^{\circ} \mathrm{C}$. J. Chem. Phys. 101: 6964-6974. https://doi.org/10.1063/1.468323

Leung, J.K.C. (1992). Application of shielding factors for protection against gamma radiations during a nuclear accident. IEEE Trans. Nucl. Sci. 39: 1512-1518. https://doi.org/10.1109/23.173235

Liu, C., Yang, J., Ji, S., Lu, Y., Wu, P. and Chen, C. (2018). 
Influence of natural ventilation rate on indoor $\mathrm{PM}_{2.5}$ deposition. Build. Environ. 144: 357-364. https://doi.org/ 10.1016/j.buildenv.2018.08.039

Lujaniene, G., Byčenkiene, S., Ščiglo, T., Povinec, P.P., Gera, M., Bartok, J. and Gažák, M. (2011). Radionuclides from the Fukushima accident in europe-modelling the air mass transport. 2011 Eighth International Conference on Fuzzy Systems and Knowledge Discovery (FSKD), Shanghai, 2011, pp. 2707-2709. https://doi.org/10.1109/ FSKD.2011.6020078

Lungu, M. (2004). Electrical separation of plastic materials using the triboelectric effect. Miner. Eng. 17: 69-75. https://doi.org/10.1016/j.mineng.2003.10.010

Masson, O., Ringer, W., Malá, H., Rulik, P., DlugoszLisiecka, M., Eleftheriadis, K., Meisenberg, O., De VismesOtt, A. and Gensdarmes, F. (2013). Size distributions of airborne radionuclides from the. Fukushima nuclear accident at several places in Europe. Environ. Sci. Technol. 47: 10995-11003. https://doi.org/10.1021/es401973c

Matthews, J.C., Wright, M.D., Biddiscombe, M.F., Usmani, O.S. and Henshaw, D.L. (2011). Aerosol charge state characterisation using an ELPI. J. Phys. Conf. Ser. 301: 012026. https://doi.org/10.1088/1742-6596/301/1/012026

Mayya, Y.S., Tripathi, S.N. and Khan, A. (2002). Boundary conditions and growth of mean charges for radioactive aerosol particles near absorbing surfaces. J. Aerosol Sci. 33: 781-795. https://doi.org/10.1016/s0021-8502(01)002 13-0

Mayya, Y.S., Sapra, B.K., Khan, A. and Sunny, F. (2004). Aerosol removal by unipolar ionization in indoor environments. J. Aerosol Sci. 35: 923-941. https://doi.org/10.1016/j.jaerosci.2004.03.001

McKenzie, T. and Dulai, H. (2017). Fukushima-derived radiocesium fallout in Hawaiian soils. J. Environ. Radioact. 180: 106-113. https://doi.org/10.1016/j.jenvrad.2017.10. 003

McMurry, P.H. and Rader, D.J. (1985). Aerosol wall losses in electrically charged chambers. Aerosol Sci. Technol. 4: 249-268. https://doi.org/10.1080/02786828508959054

Nazaroff, W.W. (2004). Indoor particle dynamics. Indoor Air 14: 175-183. https://doi.org/10.1111/j.1600-0668.20 04.00286.x

Persily, A.K. (2016). Field measurement of ventilation rates. Indoor Air 26: 97-111. https://doi.org/10.1111/ina.12193

Potiriadis, C., Anagnostakis, M.J., Clouvas, A., Eleftheriadis, K., Florou, E., Housiadas, C., Ioannides, K., Ioannidou, A., Karangelos, D.I., Karfopoulos, K.L., Kehagia, K., Kolovou, M., Kritidis, P., Manolopoulou, M., Papastefanou, K., Savva, M.I., Simopoulos, S.E., Stamoulis, K., Stoulos, S., Xanthos, S. and Xarchoulakos, D. (2013). Environmental measurements and inspections on imported foods and feedstuffs in Greece after the Fukushima accident. Radiat. Prot. Dosim. 156: 465-474. https://doi.org/10.1093/rpd/n ct094

Querfeld, R., Pasi, A.E., Shozugawa, K., Vockenhuber, C., Synal, H.A., Steier, P. and Steinhauser, G. (2019). Radionuclides in surface waters around the damaged Fukushima Daiichi NPP one month after the accident: Evidence of significant tritium release into the environment.
Sci. Total Environ. 689: 451-456. https://doi.org/10.1016/ j.scitotenv.2019.06.362

Schery, S.D. (2001). Understanding radioactive aerosols and their measurement. Springer Netherlands.

Shimada, M., Okuyama, K., Kousaka, Y., Okuyama, Y. and Seinfeld, J.H. (1989). Enhancement of brownian and turbulent diffusive deposition of charged aerosol particles in the presence of an electric field. J. Colloid Interface Sci. 128: 157-168. https://doi.org/10.1016/0021-9797(89 )90394-9

Stein, R.L., Ryback, W.H. and Sparks, A.W. (1973). Deposition of aerosol in a plastic chamber. J. Colloid Interface Sci. 42: 441-447. https://doi.org/10.1016/00219797(73)90310-X

Tan, Y., Ishikawa, T., Janik, M., Tokonami, S., Hosoda, M., Sorimachi, A. and Kearfott, K. (2015). Novel method for estimation of the indoor-to-outdoor airborne radioactivity ratio following the Fukushima Daiichi Nuclear Power Plant accident. Sci. Total Environ. 536: 25-30. https://doi.org/10.1016/j.scitotenv.2015.07.034

Thatcher, T.L., Lai, A.C.K., Moreno-Jackson, R., Sextro, R.G. and Nazaroff, W.W. (2002). Effects of room furnishings and air speed on particle deposition rates indoors. Atmos. Environ. 36: 1811-1819. https://doi.org/ 10.1016/S1352-2310(02)00157-7

Thomas, G.A., Bethel, J.A., Galpine, A., Mathieson, W., Krznaric, M. and Unger, K. (2011). Integrating research on thyroid cancer after Chernobyl--the Chernobyl Tissue Bank. Clin. Oncol. 23: 276-281. https://doi.org/10.1016/ j.clon.2011.01.503

Tinkle, M.D. and Barlow, S.E. (2001). Image charge forces inside conducting boundaries. J. Appl. Phys. 90: 16121624. https://doi.org/10.1063/1.1383016

Turner, J.R., Liguras, D.K. and Fissan, H.J. (1989). Clean room applications of particle deposition from stagnation flow: Electrostatic effects. J. Aerosol Sci. 20: 403-417. https://doi.org/10.1016/0021-8502(89)90074-8

Wang, Y., Li, A., Fan, X., Lu, S. and Shang, L. (2019). Effects of surface properties of vertical textiles indoors on particle deposition: A small-scale chamber study. Aerosol Air Qual. Res. 19: 885-895. https://doi.org/10.4209/aaqr. 2018.08.0321

Waring, M.S. and Siegel, J.A. (2011). The effect of an ion generator on indoor air quality in a residential room. Indoor Air 21: 267-276. https://doi.org/10.1111/j.16000668.2010.00696.x

Wistrom, A.O. and Khachatourian, A.V. (2001). Electrostatic Interaction between Unlike Aerosols. Aerosol Sci. Technol. 35: 865-873. https://doi.org/10.1080/02786820 126848

Wu, C.C., Lee, G.W.M., Cheng, P., Yang, S. and Yu, K.P. (2006). Effect of wall surface materials on deposition of particles with the aid of negative air ions. J. Aerosol Sci. 37: 616-630. https://doi.org/10.1016/j.jaerosci.2005.05.018

Wu, Y., Castle, G.S.P. and Inculet, I.I. (2005). Particle size analysis in the study of induction charging of granular materials. J. Electrostat. 63: 189-202. https://doi.org/10. 1016/j.elstat.2004.09.008

Yoshida-Ohuchi, H., Kanagami, T., Satoh, Y., Hosoda, M., 
Naitoh, Y. and Kameyama, M. (2016). Indoor radiocaesium contamination in residential houses within evacuation areas after the Fukushima nuclear accident. Sci. Rep. 6: 26412. https://doi.org/10.1038/srep26412
Received for review, March 6, 2020

Revised, July 31, 2020 Accepted, August 4, 2020 